\title{
Fatty Acid Composition of Egg Yolk from Chickens Fed a Diet including Marigold (Tagetes erecta $\mathrm{L}_{\text {.) }}$
}

\author{
A. Altuntaş ${ }^{1}$ and R. Aydin ${ }^{2}$ \\ ${ }^{1}$ Department of Animal Sciences, Faculty of Agriculture, Kahramanmaras Sutcu Imam University, Avsar, \\ 46100 Kahramanmaras, Turkey \\ ${ }^{2}$ Department of Animal Nutrition and Nutritional Diseases, Faculty of Veterinary Medicine, Balikesir University, \\ Campus of Cagis, 10145 Balikesir, Turkey
}

Correspondence should be addressed to R. Aydin; rahimaydin@yahoo.com

Received 23 July 2014; Accepted 26 November 2014; Published 22 December 2014

Academic Editor: Javier S. Perona

Copyright (C) 2014 A. Altuntaş and R. Aydin. This is an open access article distributed under the Creative Commons Attribution License, which permits unrestricted use, distribution, and reproduction in any medium, provided the original work is properly cited.

\begin{abstract}
The objective of this study was to determine the effects of diet supplemented with marigold on egg yolk fatty acid composition and egg quality parameters. Sixty hens were assigned into three groups and fed diets supplemented with 0 (control), $10 \mathrm{~g} \mathrm{~kg}^{-1}$, or $20 \mathrm{~g} \mathrm{~kg}^{-1}$ marigold for 42 days. Eggs collected at the 6 th week of the study were analyzed for fatty acid analysis. Laying performance, egg quality parameters, and feed intake were also evaluated. Yolk color scores in the group fed the $20 \mathrm{~g} \mathrm{~kg}^{-1}$ marigold-supplemented diet were found greater than control (10.77 versus 9.77). Inclusion of $20 \mathrm{~g} \mathrm{~kg}^{-1}$ marigold in diet influenced egg weights adversely compared to the control. Diet supplemented with $10 \mathrm{~g} \mathrm{~kg}^{-1}$ or $20 \mathrm{~g} \mathrm{~kg}^{-1}$ marigold increased the levels of C16:0 and C18:0 and decreased levels of C16:1 (n-7) and C18:1 (n-9) in the egg yolk. Also, diet including marigold increased total saturated fatty acids (SFA) and decreased monounsaturated fatty acids (MUFA) in the egg yolk.
\end{abstract}

\section{Introduction}

The color of egg yolk is an important parameter for consumers and is produced by carotenoid pigments in the feed. The yolk color depends not only on the levels of pigmenting substances, namely, xanthophylls, present in the feed, but also on the type and the ratio of these compounds [1]. There are different sources of xanthophylls used for egg yolk pigmentation. Poultry cannot synthesize these compounds and must obtain carotenoids from their diets [2]. Most of the natural carotenoids that are relevant for poultry pigmentation occur in the free form, but the lutein in Tagetes sp. occurs mainly as diesters of palmitic and myristic acids [3]. Since laying hens have the ability to transport 20 to $600 \mathrm{mg} \mathrm{g}^{-1}$ of these pigments into their egg yolks from the ingested feed, pigments of either natural or synthetic origins are added to hen diets to achieve the desired egg yolk color [4]. The use of synthetic pigment in the diet increases feed cost. Therefore, natural carotenoids may be considered as pigmenting agents for egg yolk. One of them is marigold which is rich in yellow xanthophylls, mainly lutein and zeaxanthin [5].

Marigold (Tagetes erecta L.) is a native plant commonly used in the pigmentation of eggs $[6,7]$ and contains total carotenoid of $4200 \mathrm{mg} / \mathrm{kg}$ [8]. The marigold flour was used at the levels of $16 \mathrm{~g} \mathrm{~kg}^{-1}, 24 \mathrm{~g} \mathrm{~kg}^{-1}$, or $32 \mathrm{~g} \mathrm{~kg}^{-1}$ for pigmentation in rainbow trouts (Oncorhynchus mykiss) and the level of $16 \mathrm{~g} \mathrm{~kg}^{-1}$ of marigold flour was found to be sufficient for pigmentation [9]. There have been a number of studies related to egg yolk pigmentation and egg production in poultry. In a study conducted on laying chickens, marigold flour was added into basal diet at the levels of $8 \mathrm{~g} \mathrm{~kg}^{-1}$ or $12 \mathrm{~g} \mathrm{~kg}^{-1}$ to evaluate the effect of marigold flour on yolk color and egg production in laying chickens [10]. In a recent study, effect of nonsaponified lutein from marigold flour and saponified lutein from marigold flower extract on chicken egg yolk coloration was evaluated [11]. And it was concluded that 
TABLE 1: Composition of the experimental $\operatorname{diets}^{1}$ (as dry-matter basis).

\begin{tabular}{lccc}
\hline \multicolumn{4}{c}{ Supplementation of Tagetes erecta L. $(\mathrm{g} / \mathrm{kg})$} \\
Feed ingredients & 0 & 10 & 20 \\
\hline Corn & 420.5 & 420.5 & 420.5 \\
Barley & 120 & 120 & 120 \\
Soybean meal & 124 & 124 & 124 \\
Sunflower meal & 100 & 100 & 100 \\
Wheat middlings & 120 & 110 & 100 \\
Tagetes erecta L. & 0 & 10 & 20 \\
Vegetable oil & 14 & 14 & 14 \\
Limestone & 82 & 82 & 82 \\
Dicalcium phosphate & 12 & 12 & 12 \\
Lysine & 0.5 & 0.5 & 0.5 \\
DL-Methionine & 1 & 1 & 1 \\
NaCl & 2.5 & 2.5 & 2.5 \\
Vitamin premix & 2.5 & 2.5 & 2.5 \\
\hline Total & 1,000 & 1,000 & 1,000 \\
\hline
\end{tabular}

${ }^{1}$ Diets contained per kilogram of diet: vitamin A, $8000 \mathrm{IU} / \mathrm{kg}$; vitamin D, $1500 \mathrm{IU} / \mathrm{kg}$; riboflavin, $4 \mathrm{mg} / \mathrm{kg}$; cobalamin, $10 \mathrm{ug} / \mathrm{kg}$; vitamin E, $15 \mathrm{mg} / \mathrm{kg}$; vitamin $\mathrm{K}, 2 \mathrm{mg} / \mathrm{kg}$; choline, $500 \mathrm{mg} / \mathrm{kg}$; niacin, $25 \mathrm{mg} / \mathrm{kg}$; manganese, $60 \mathrm{mg} / \mathrm{kg}$; zinc, $50 \mathrm{mg} / \mathrm{kg}$.

dietary lutein enhances yolk color at levels of approximately 30 to $40 \mathrm{~g} \mathrm{~kg}^{-1}$ and that saponified lutein from the marigold flour extract appears to be more effective in egg yolk color than nonsaponified lutein from marigold flour [11].

However, there have been no studies reported on the effect of diets supplemented with marigold flour on egg yolk fatty acids in the poultry. Therefore, this study was conducted to evaluate the effects of marigold flour on laying hen performance, yolk fatty acids, and egg properties in chickens.

\section{Materials and Methods}

2.1. Birds and Diets. This study was conducted in the research farm at the Kahramanmaras Sutcu Imam University, Turkey. In this study, sixty 80-week-old Hyline-5 laying hens were randomly assigned to three groups with four replicates of five birds each (20 laying hens per group) and fed a diet supplemented with 0 (control), 10 , or $20 \mathrm{~g} \mathrm{~kg}^{-1}$ marigold flour (Tagetes erecta L.) for 42 days (Table 1). Dried flowers were used after being crushed by using a grinder. Water and feed were provided ad libitum during the study. The photoperiod was maintained at 16L:8D throughout the study. Body weights of laying hens were determined at the beginning and end of the study.

Feed consumption was recorded on a subgroup basis at weekly intervals. Feed conversion ratio (FCR) was calculated on weekly basis for every group in the study and was expressed as kilogram of feed consumed per kilogram of egg produced. Eggs were examined for interior and exterior quality. Twelve eggs per group (three eggs per replicate) were collected at the end of the study for measuring egg components and parameters. Egg weight, yolk and albumen index, shape index, albumen weight, yolk weight, and shell weight were measured. Albumen height was measured by a tripod micrometer, albumen length and width were measured by a compass, and then the albumen index was calculated according to the following formula:

$$
\begin{aligned}
& \text { Albumen index } \\
& =\text { albumen height } \\
& \qquad \times\left(\left[\left(\frac{\text { long diameter of albumen }}{2}\right.\right.\right. \\
& \left.\left.\left.\quad+\frac{\text { short diameter of albumen }}{2}\right)\right]\right)^{-1} \times 100 .
\end{aligned}
$$

Yolk height and yolk diameter were measured by the same instrument and yolk index was calculated with the following formula: yolk index = yolk height/[(long diameter of yolk + short diameter of yolk)/2] $\times 100$. Shape index was calculated according to the following formula: shape index $=$ (short border/long border $) \times 100$. Shell thickness was measured by a micrometer (Mitutoyo, $0.01 \mathrm{~mm}$, Japan). Shell thickness was a mean value of measurements at three locations on the eggs (air cell, equator, and sharp end). Pigmentation of the egg yolk was measured visually using the Roche color fan (RCF) scale (Roche Ltd., Basel, Switzerland).

2.2. Egg Fatty Acid Analysis. Three samples of eggs from each dietary group were obtained randomly for fatty acid analysis at the end of the sixth week of the feeding study. Fatty acid methyl esters (FAMEs) were prepared using methanol $/ 2 \mathrm{~N}$ $\mathrm{NaOH}$ and extracted with n-hexane and then analyzed by gas chromatography (GC). For this purpose, samples were injected into a Supelcowax 10 column $(60 \mathrm{~m}-0.25 \mathrm{~mm}$ i.d., $0.25 \mathrm{~lm}$ film thickness; Supelco, Bellefonte, PA, USA) coated with polyethylene glycol. The column was connected to a Hewlett-Packard 5890 Series II (Little Falls, Wilmington, DE, USA) GC equipped with a flame-ionization detector. The oven temperature was programmed as follows: $180^{\circ} \mathrm{C}$ for $2 \mathrm{~min}$, which increased to $200^{\circ} \mathrm{C}$ at $2^{\circ} \mathrm{C} / \mathrm{min}$, held at $200^{\circ} \mathrm{C}$ for a further $10 \mathrm{~min}$, and then increased to $215^{\circ} \mathrm{C}$ at $2^{\circ} \mathrm{C} / \mathrm{min}$ and kept there for $10 \mathrm{~min}$. The injector and detector temperatures were $200^{\circ} \mathrm{C}$ and $250^{\circ} \mathrm{C}$, respectively. Helium was used as the carrier gas at a flow rate of $1.5 \mathrm{~mL} / \mathrm{min}$. FAME identification was based on retention times compared with thoseof standard FAMEs. C17:0 was used as an internal standard.

2.3. Statistical Analysis. One-way analysis of variance (ANOVA) was carried out to determine the effects of marigold flour on egg production, egg weight, feed conversion ratio, egg yolk fatty acid composition, and egg quality parameters in laying chickens. Significance between individual means was identified using the Tukey's multiple range test. Mean differences were considered significant at $P<0.05$.

\section{Results}

The effect of supplementing diets with marigold flour on body weight, feed consumption, egg production, and egg weight 
TABLE 2: The effects of Tagetes erecta L. supplementation on body weight, feed consumption, egg production, and egg weight.

\begin{tabular}{lcccc}
\hline \multicolumn{5}{c}{ Supplementation of Tagetes erecta $\mathrm{L} .(\mathrm{g} / \mathrm{kg})$} \\
& 0 & 10 & 20 & SEM \\
\hline Initial body weight $(\mathrm{g})$ & 1259 & 1279 & 1250 & 24 \\
Final body weight $(\mathrm{g})$ & 1316 & 1320 & 1270 & 28 \\
Feed consumption g/bird & 128.1 & 123.57 & 117.26 & 3.87 \\
Egg production (\%) & 72.0 & 76.67 & 71.33 & 2.93 \\
Egg weight (g) & $70.69^{\mathrm{a}}$ & $70.21^{\mathrm{a}}$ & $67.97^{\mathrm{b}}$ & 0.31 \\
\hline${ }^{1}$ Diets were supplemented with 0, 10, or $20 \mathrm{~g} / \mathrm{kg}$ marigold flower for 6 weeks. \\
${ }^{\mathrm{a}, \mathrm{b}}$ Values are expressed as means and without a common superscript are \\
significantly different within a row $(P<0.05)$.
\end{tabular}

TABLe 3: The effects of diets supplemented with different levels of Tagetes erecta $\mathrm{L}$. on the egg parameters ${ }^{1}$.

\begin{tabular}{lcccc}
\hline \multicolumn{5}{c}{ Supplementation of Tagetes erecta L. (g/kg) } \\
& 0 & 10 & 20 & SEM \\
\hline Egg weight (g) & 69.67 & 69.99 & 68.58 & 1.02 \\
Albumen weight (g/egg) & 45.27 & 44.28 & 43.06 & 1.20 \\
Yolk weight (g/egg) & 18.80 & 18.71 & 18.78 & 0.23 \\
Shell weight (g/egg) & 6.64 & 6.69 & 6.72 & 0.17 \\
Yolk \% & 27.44 & 26.98 & 27.53 & 0.41 \\
Albumen \% & 64.49 & 63.43 & 62.62 & 0.87 \\
Shell \% & 9.58 & 9.58 & 9.83 & 0.24 \\
Albumen index & 7.87 & 7.80 & 7.32 & 0.31 \\
Yolk index & 41.99 & 40.86 & 40.67 & 0.53 \\
Shape index & 73.50 & 73.41 & 73.77 & 0.38 \\
Haugh unit & 69.54 & 68.79 & 67.85 & 1.96 \\
Shell thickness $\left(\mathrm{mm} \cdot 10^{-2}\right)$ & 0.36 & 0.36 & 0.38 & 0.01 \\
Shell strength $\left(\mathrm{kg} / \mathrm{cm}^{2}\right)$ & $1.03^{\mathrm{b}}$ & $1.32^{\mathrm{a}}$ & $1.15^{\mathrm{ab}}$ & 0.09 \\
${ }^{2}$ RCF values & $9.77^{\mathrm{b}}$ & $10.40^{\mathrm{ab}}$ & $10.77^{\mathrm{a}}$ & 0.18 \\
\hline
\end{tabular}

${ }^{1}$ Eggs were collected in last week of the study and values are expressed as means and without a common superscript are significantly different within a row $(P<0.05)$.

${ }^{2}$ RCF: Roche color fan.

is shown in Table 2. Inclusion of marigold flour in the diets did not affect final body weight, feed consumption, or egg production of the chickens compared to the control group. However, supplementing high level of marigold flour into the diet significantly reduced egg weight compared to the control and the laying hens fed the diet containing the lower level of marigold flour. Inclusion of marigold flour at the high level of marigold significantly decreased egg weight for every week starting from week one compared to the control (not shown here).

The effect of dietary marigold flour on egg parameters in laying hens is shown in Table 3. Inclusion of marigold in the diet had no effect on any egg parameters, except shell strength and yolk color of the eggs. Shell strength of the eggs from hens fed $10 \mathrm{~g} \mathrm{~kg}^{-1}$ marigold flour is significantly greater than the control $(P<0.05)$ and $20 \mathrm{~g} \mathrm{~kg}^{-1}$ marigold supplementation to diet showed a yolk color score of 10.77 , which was higher than the control score of $9.77(P<0.05)$.
TABLE 4: The effects of Tagetes erecta L. supplementation on the fatty acid composition of egg yolks ${ }^{1}$.

\begin{tabular}{|c|c|c|c|c|}
\hline \multicolumn{5}{|c|}{ Supplementation of Tagetes erecta L. (g/kg) } \\
\hline Fatty acids & 0 & 10 & 20 & SEM \\
\hline C14:0 & 0.36 & 0.35 & 0.36 & 0.01 \\
\hline $\mathrm{C} 16: 0$ & $24.75^{\mathrm{b}}$ & $25.76^{\mathrm{a}}$ & $25.60^{\mathrm{a}}$ & 0.04 \\
\hline $\mathrm{C} 16: 1(\mathrm{n}-7)$ & $3.30^{\mathrm{a}}$ & $3.15^{\mathrm{b}}$ & $2.77^{\mathrm{c}}$ & 0.01 \\
\hline C18:0 & $7.30^{\mathrm{c}}$ & $8.02^{\mathrm{b}}$ & $8.76^{\mathrm{a}}$ & 0.04 \\
\hline $\mathrm{C} 18: 1(\mathrm{n}-9 \mathrm{t})$ & 0.13 & 0.14 & 0.14 & 0.01 \\
\hline $\mathrm{C} 18: 1(\mathrm{n}-9 \mathrm{c})$ & $44.90^{\mathrm{a}}$ & $43.25^{\mathrm{b}}$ & $42.87^{\mathrm{c}}$ & 0.04 \\
\hline $\mathrm{C} 18: 2(\mathrm{n}-6)$ & 16.46 & 16.54 & 16.59 & 0.05 \\
\hline$\gamma \mathrm{C} 18: 3(\mathrm{n}-6)$ & 0.14 & 0.15 & 0.17 & 0.01 \\
\hline$\alpha \mathrm{C} 18: 3(\mathrm{n}-3)$ & 0.54 & 0.50 & 0.53 & 0.02 \\
\hline C20:1 (n-9) & 0.26 & 0.26 & 0.26 & 0.01 \\
\hline C20:2 (n-6) & 0.15 & 0.15 & 0.17 & 0.01 \\
\hline C20:3 (n-3) & 0.16 & 0.16 & 0.16 & 0.01 \\
\hline $\mathrm{C} 22: 2(\mathrm{n}-6)$ & $1.17^{\mathrm{b}}$ & $1.19^{\mathrm{ab}}$ & $1.23^{\mathrm{a}}$ & 0.01 \\
\hline C22:6 (n-3) & 0.38 & 0.38 & 0.39 & 0.01 \\
\hline$\sum \mathrm{SFA}$ & $32.41^{c}$ & $34.12^{\mathrm{b}}$ & $34.72^{\mathrm{a}}$ & 0.03 \\
\hline$\sum$ MUFA & $48.59^{\mathrm{a}}$ & $46.80^{\mathrm{b}}$ & $46.04^{c}$ & 0.04 \\
\hline$\sum$ PUFA & 19.00 & 19.08 & 19.24 & 0.04 \\
\hline$n-6$ & 17.92 & 18.03 & 18.16 & 0.05 \\
\hline$n-3$ & 1.08 & 1.04 & 1.08 & 0.01 \\
\hline$n-6 / n-3$ & 16.59 & 17.34 & 16.89 & 0.25 \\
\hline SFA/MUFA & $0.67^{\mathrm{b}}$ & $0.73^{\mathrm{b}}$ & $0.75^{\mathrm{a}}$ & 0.002 \\
\hline
\end{tabular}

${ }^{1}$ Yolk samples of three fresh eggs from each treatment were obtained at the end of the study.

a,b,c Means within a row for each variable with no common letter differ $(P<$ $0.05)$.

$\sum \mathrm{SFA}=$ total saturated fatty acids; $\sum$ MUFA $=$ total monounsaturated fatty acids; $\sum$ PUFA = total polyunsaturated fatty acids; $n-6$ : omega- 6 fatty acids; n-3: omega-3 fatty acids.

Table 4 shows the fatty acid composition of eggs from laying hens fed diets supplemented with 0,10 , or $20 \mathrm{~g} \mathrm{~kg}^{-1}$ marigold flour. Inclusion of marigold in the diet at either level significantly $(P<0.01)$ increased the levels of C16:0 and C18:0 in the egg yolk while at the same time decreased the levels of C16:1 (n-7) and C18:1 (n-9) $(P<0.01)$. Yolk from hens fed a diet including $20 \mathrm{~g} \mathrm{~kg}^{-1}$ marigold had a higher level of C22:2 (n-6) $(P<0.05)$ when compared to the control. Also, eggs from chickens fed diets including $10 \mathrm{~g} \mathrm{~kg}^{-1}$ or $20 \mathrm{~g} \mathrm{~kg}^{-1}$ marigold flour had higher level of SFA and lower level of MUFA $(P<0.05)$ when compared to the control.

\section{Discussion}

Marigold (Tagetes erecta L.) was reported to be a good source of xanthophylls $[6,7]$ and used for pigmentation of the egg yolks and poultry skin $[12,13]$. Recently, it was shown that inclusion of $40 \mathrm{~g} \mathrm{~kg}^{-1}$ of marigold flour in the diet of laying pullets did not reduce external quality of eggs and there were no effects on body weight, hen day egg production, egg weight, or feed conversion rate [14]. The findings of the present study on body weight, hen egg production, and feed consumption are in agreement with those reported in 
the previous studies $[10,14]$. However, in the present study inclusion of $20 \mathrm{~g} \mathrm{~kg}^{-1}$ marigold flour into the diets caused a decrease in egg size compared to the control for an unknown reason.

Inclusion of marigold flour in the diets for pigmentation of egg yolk and poultry meat has been widely documented $[1,6,7,10-14]$. In the present study, inclusion of marigold in the diet had no effect on egg shell weight, Haugh units, yolk weight, albumen weight, and shell thickness. These findings agree with the previous studies reporting no change in egg quality after inclusion of marigold flour into laying hens' diet [13]. In this study, use of marigold flour in the diet of chicken had no detrimental effect on internal and external quality of egg as well as egg production characteristics.

These results of the present study cannot be compared with data in the literature since there are no reports on the effects of marigold flour on yolk fatty acid composition in poultry. In the present study, inclusion of marigold in the diet significantly increased SFA, mainly C16:0 and C18:0, and decreased MUFA, mainly C16:1 (n-7) and C18:1 (n9). Similar to the present study, in a study conducted in rainbow trout, it was shown that marigold flour significantly increased C16:0 and C18:0 $(P<0.05)$. In the same study it was shown that inclusion of $18 \mathrm{~g} \mathrm{~kg}^{-1}$ marigold flour in the diet significantly decreased C16:1 (n-7) and C18:1 (n9) [15]. Therefore, this study may suggest that inclusion of marigold flour in the laying hens' diet increased the ratio of SFA to MUFA by downregulating stearoyl-CoA desaturase, an enzyme converting C16:0 and C18:0 into C16:1 (n-7) and C18:1 (n-9), respectively.

In conclusion, certain fatty acids such as conjugated linoleic acid and conjugated trienoic acids were shown to inhibit SCD [16, 17]. As known, marigold contains naturally occurring conjugated triene fatty acid, calendic acid, to be believed to inhibit the enzyme stearoyl-CoA desaturase. In the future studies, the effects of marigold on stearoyl-CoA desaturase should be investigated.

\section{Conflict of Interests}

The authors declare that there is no conflict of interests regarding the publication of this paper.

\section{Acknowledgment}

This study was a part of M.S. by A. Altuntaş (2010) and was supported by the Scientific Research Project Committee of Kahramanmaras Sutcu Imam University, Turkey, Grant no. 2009/3-13YLS.

\section{References}

[1] J. Galobart, R. Sala, X. Rincón-Carruyo, E. G. Manzanilla, B. Vilà, and J. Gasa, "Egg yolk color as affected by saponification of different natural pigmenting sources," Journal of Applied Poultry Research, vol. 13, no. 2, pp. 328-334, 2004.

[2] A. Blanch, "Getting the color of yolk and skin right," World's Poultry Science Journal, vol. 15, no. 9, pp. 32-33, 1999.
[3] H. Hencken, "Chemical and physiological behavior of feed carotenoids and their effects on pigmentation," Poultry Science, vol. 71, no. 4, pp. 711-717, 1992.

[4] I. Bartov and S. Bornstein, "Studies on egg yolk pigmentation. 2. Effect of ethoxyquin on xanthophyll utilization," Poultry Science, vol. 45, no. 2, pp. 297-305, 1966.

[5] H. Karunajeewa, R. J. Hughes, M. W. McDonald, and F. S. Shenstone, "A review of factors influencing pigmentation of egg yolks," World's Poultry Science Journal, vol. 40, pp. 52-65, 1984.

[6] D. Narahari, K. Venugopal, P. Kothandaraman, and R. Kumararaj, "Marigold flower meal as a source of xanthophylls for egg yolk pigmentation," Indian Journal of Poultry Science, vol. 16, pp. 409-411, 1981.

[7] O. M. A. Ojeda, G. E. Avila, and A. F. J. Tirado, "Waste pulp from whole marigold (Tagestes erecta) flowers in diets for poultry," Veterinaria México, vol. 14, pp. 145-149, 1983.

[8] M. Göçer, M. Yanar, M. Kumlu, and Y. Yanar, "The effects of red pepper, marigold flower, and synthetic astaxanthin on pigmentation, growth, and proximate composition of Penaeus semisulcatus," Turkish Journal of Veterinary and Animal Sciences, vol. 30, no. 4, pp. 359-365, 2006.

[9] H. M. Büyükçapar, M. Yanar, and Y. Yanar, "Pigmentation of rainbow trout (Oncorhynchus mykiss) with carotenoids from marigold flower (Tagetes erecta) and red pepper (Capsicum annum)," Turkish Journal of Veterinary and Animal Sciences, vol. 31, no. 1, pp. 7-12, 2007.

[10] E. Rowghani, A. Maddahian, and M. A. Abousadi, "Effects of addition of marigold flower, safflower petals, red pepper on eggyolk color and egg production in laying hens," Pakistan Journal of Biological Sciences, vol. 9, no. 7, pp. 1333-1337, 2006.

[11] K. Lokaewmanee, K.-E. Yamauchi, T. Komori, and K. Saito, "Enhancement of yolk color in raw and boiled egg yolk with lutein from marigold flower meal and marigold flower extract," The Journal of Poultry Science, vol. 48, no. 1, pp. 25-32, 2011.

[12] F. Sirri, N. Iaffaldano, G. Minelli, A. Meluzzi, M. P. Rosato, and A. Franchini, "Comparative pigmentation efficiency of high dietary levels of apo-ester and marigold extract on quality traits of whole liquid egg of two strains of laying hens," Journal of Applied Poultry Research, vol. 16, no. 3, pp. 429-437, 2007.

[13] S. D. Chowdhury, B. M. Hassin, S. C. Das, M. H. Rashid, and A. J. M. Ferdaus, "Evaluation of marigold flower and orange skin as sources of xanthophyll pigment for the improvement of egg yolk color," The Journal of Poultry Science, vol. 45, no. 4, pp. 265-272, 2008.

[14] B. M. Hasin, A. J. M. Ferdaus, M. A. Islam, M. J. Uddin, and M. S. Islam, "Marigold and orange skin as egg yolk color promoting agents," Indian Journal of Poultry Science, vol. 5, no. 10, pp. 979987, 2006.

[15] Y. Yanar, H. Büyükçapar, M. Yanar, and M. Göcer, "Effect of carotenoids from red pepper and marigold flower on pigmentation, sensory properties and fatty acid composition of rainbow trout," Food Chemistry, vol. 100, no. 1, pp. 326-330, 2007.

[16] Y. Park, J. M. Storkson, J. M. Ntambi, M. E. Cook, C. J. Sih, and M. W. Pariza, "Inhibition of hepatic stearoyl-CoA desaturase activity by trans-10, cis-12 conjugated linoleic acid and its derivatives," Biochimica et Biophysica Acta: Molecular and Cell Biology of Lipids, vol. 1486, no. 2-3, pp. 285-292, 2000.

[17] K. Arao, Y.-M. Wang, N. Inoue et al., "Dietary effect of pomegranate seed oil rich in 9cis, 11trans, 13cis conjugated linolenic acid on lipid metabolism in obese, hyperlipidemic OLETF Rats," Lipids in Health and Disease, vol. 3, article 24, 2004. 

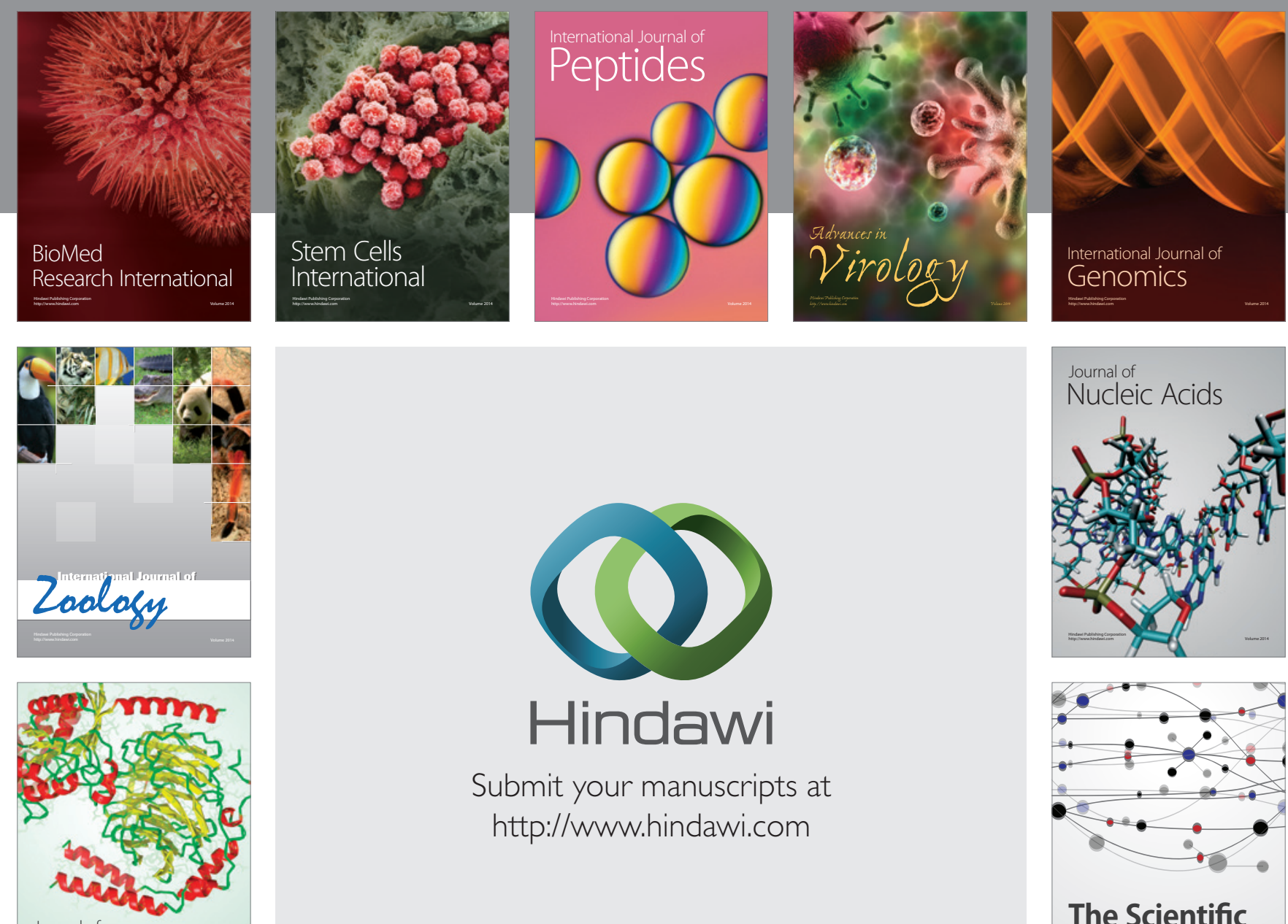

Submit your manuscripts at

http://www.hindawi.com

Journal of
Signal Transduction
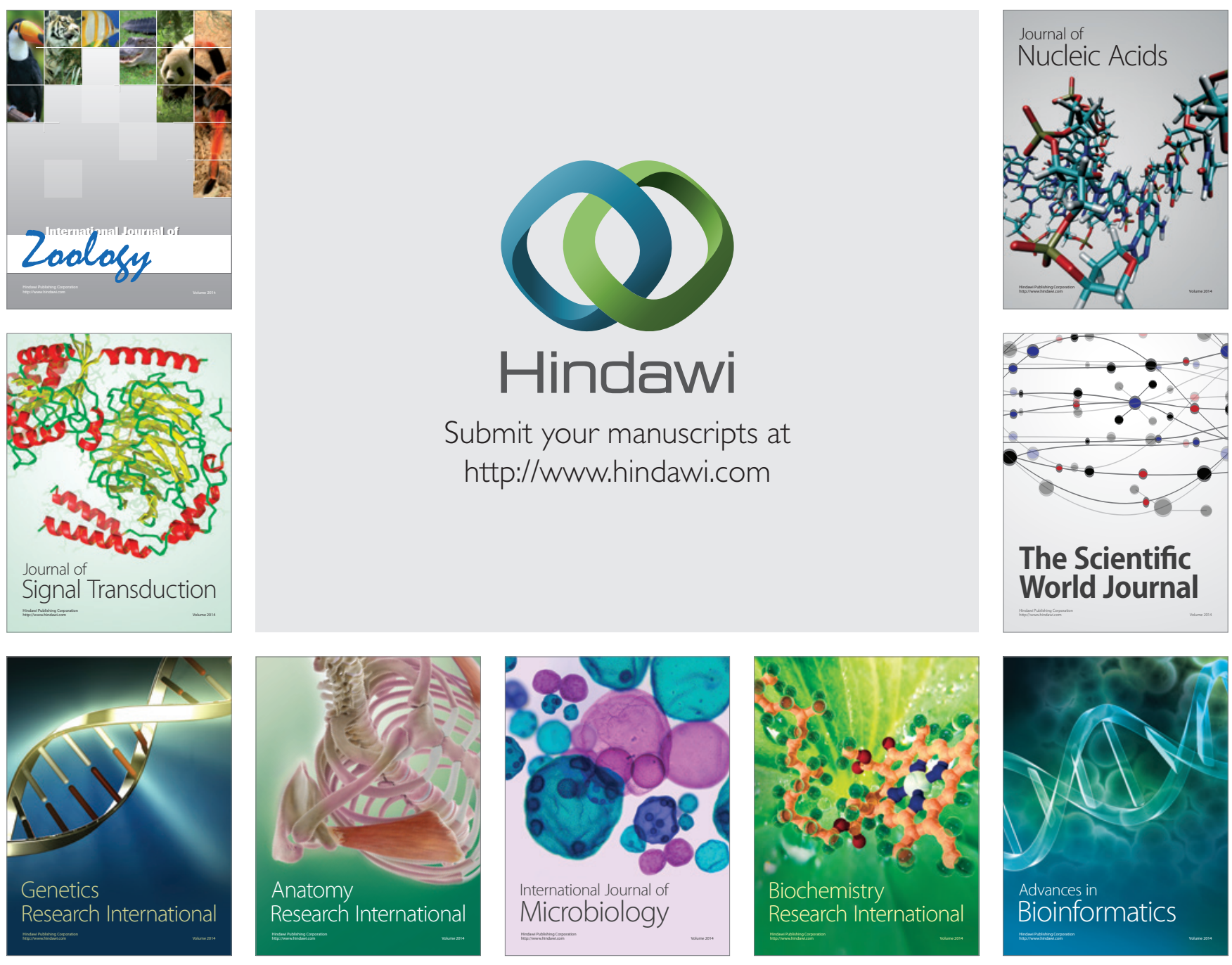

The Scientific World Journal
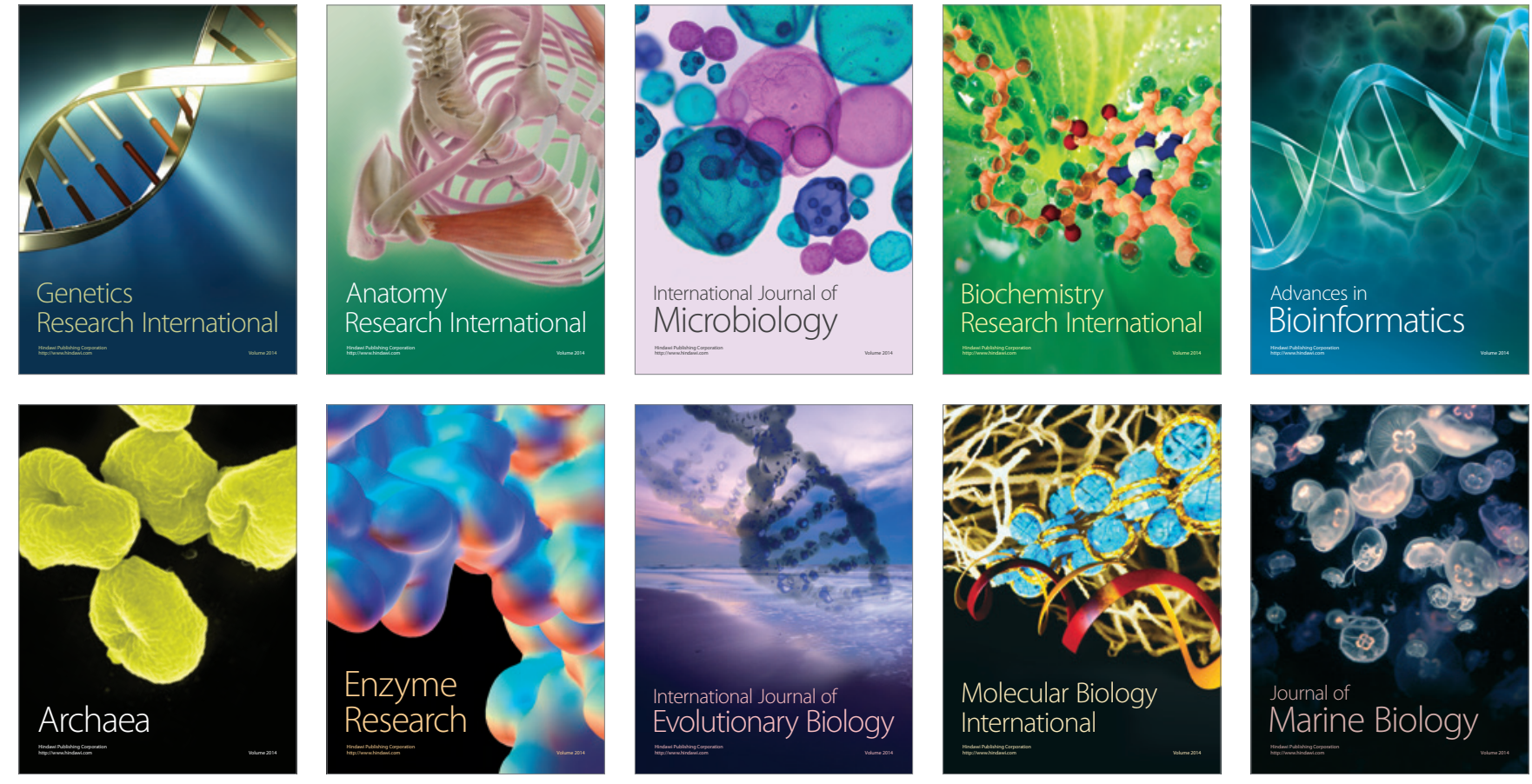